\title{
Construction of Risks Prevention Mechanism of Architectural Engineering Project

\author{
Yupeng Yang
}

Master of Science in Management,lecturer,Architecture Engineering Department ,at Logistics University of Chinese People's Armed Police Force,Tianjin,300309,China

hunter2011@foxmail.com

Keywords: Architectural Engineering, Risk Evaluation, Risk Prevention.

\begin{abstract}
Because of large investment, long construction period, complex technology, numerous participation and many unpredictable factors in engineering, so construction project is a career which has high risks. Firstly, we establish an engineering project risk evaluation system, and then establish the construction risk assessment model with fuzzy evaluation method, and finally propose some risk prevention measures for architecture engineering project.
\end{abstract}

\section{Introduction}

The implementation of construction project is a one-time, innovative process, and involves many factors and variables. These features make the construction enterprises encounter with various risks in the project implementation process. In China, the construction industry has been an industry which needs extensive management, manual operation, and low-technology. Although the research on project risk management is increasingly received more attention, the construction project risk management lagged behind. To some extent, this has affected the development of China's construction industry and construction enterprises going to the world. In order to adapt to the increasingly fierce market completion of construction enterprises, integrate with the international construction industry gradually, and improve capacity to resist risks, we must strengthen the research and the realization of construction project risk management.

\section{Engineering Project Risk System}

Decision risks. (1) Information identification. Almost every day there will be a number of international and domestic engineering bidding or contract information. Most of the information is real, but whether it is worth capturing and tracking is not necessarily. Furthermore, some false information in the construction market is very confusing. If not carefully identify it, it is likely to cause heavy losses.

(2) Intermediaries and agents. In project contracting process, in order to obtain their own interests, some intermediaries and agents will hide some real information. Therefore, selection of reliable agent is very important. Improper selection or unreasonable agency agreement will cause major losses to the contractor. What intermediaries care is project transaction, but not project risks.

(3) Bid quotation. Bidding strategy is an effective method for the contractor to get the project. If there is an error or improper strategy application, potential risks will be hidden in the project construction process.

Compliance risks. (1) Contract terms. Almost all countries in the international community have developed a model contract for architectural engineering construction, and any model contract are inseparable from responsibility, authority and rights of the parties. Potential risks in contract terms are often caused by unclear responsibility or unknown rights.

(2) Engineering management. Engineering management is usually not difficult for experienced contractors. However, in large complex engineering, there are many implementation sub-contractors and intricate process, as well as unexpected changes in geological, hydrological and natural conditions, so the contractor will face many risks. 
(3) Contract management. Contract management is the key for the contractor's profit. Contract management is mainly to protect themselves by the use of contract terms. It requires profound knowledge and skills.

Financial risks. (1) Material management. Material management is directly related to the success of the project according to plan, and whether enough material can be supplied, which will affect the engineering benefit. Scientific material management should not only meet the needs of the project, but also avoid hoarding a large amount of material and taking up a lot of money.

(2) Fund management. Fund management is an important guarantee to obtain the ideal economic benefit of the project. Fund management runs through the project, because negligence or errors in any one link can lead to significant risks.

Liability risks. (1) Professional liability. Engineering contractors are considered to be with professional knowledge, and He must take responsibility for what he is doing. Professional liability of architectural construction project is mainly reflected in the engineering technology and quality.

(2) Legal liability. Legal liability includes civil liability and criminal liability. Project construction parties mainly bear the civil liability, which is undoubtly a risk for project construction parties.

Safety risks. (1) Construction site environment. Construction site environment mainly includes lighting, ventilation, noise, humidity and temperature, etc. These conditions determine Whether construction workers at its best, and directly affects the safety of the construction project.

(2) Safety operation regulations. Improving the safety operation regulations is an important guarantee to ensure the safety of the architectural construction project. In the concrete construction process, Safety management personnel and field operation personnel must follow the safety operation regulations.

(3) Safety training. Security risk management should organize construction person and field operation personnel to participate safety training. Only in accordance with the contents of safety training for construction and operation of related systems, it can ensure the safety of architectural engineering construction.

In summary, risk evaluation system of architectural engineering project is shown in Table 1:

Table 1. Risk evaluation system of architectural engineering project

\begin{tabular}{|c|c|c|}
\hline Target layer & First level indicator & Second level indicator \\
\hline \multirow{13}{*}{$\begin{array}{l}\text { Engineering project risk } \\
\text { evaluation system }\end{array}$} & \multirow{3}{*}{ Decision risks } & Information identification \\
\hline & & Intermediaries and agents \\
\hline & & Bid quotation \\
\hline & \multirow{3}{*}{ Compliance risks } & Contract terms \\
\hline & & Engineering management \\
\hline & & Contract management \\
\hline & \multirow{2}{*}{ Financial risks } & Material management \\
\hline & & Fund management \\
\hline & \multirow{2}{*}{ Liability risks } & Professional liability \\
\hline & & Legal liability \\
\hline & \multirow{3}{*}{ Safety risks } & $\begin{array}{c}\text { Construction site } \\
\text { environment }\end{array}$ \\
\hline & & $\begin{array}{l}\text { Safety operation } \\
\text { regulations }\end{array}$ \\
\hline & & Safety training \\
\hline
\end{tabular}




\section{Construction Risk Assessment Model}

Here we establish a fuzzy evaluation model, to conduct risk analysis and assessment of construction projects. Concrete steps of the construction risk assessment model are as follow:

a) Determine evaluation index system. For Multivariate risk comprehensive assessment system, establishment of evaluation index system is a prerequisite. Risk factor index selection should be carried out based on the risk identification and risk factors assessment results.

b) Establish risk factors set $U, U=\left\{\mathrm{u}_{1}, \mathrm{u}_{2}, \ldots, \mathrm{u}_{\mathrm{m}}\right\}$. In risk assessment system of complex construction projects, many risk factors should be considered, so they can be divided into several levels $\mathrm{u}_{1} \sim \mathrm{u}_{\mathrm{m}}$. These risks factors are affected by risks set $\mathrm{X}=\left\{\mathrm{X}_{1}, \mathrm{X}_{2}, \ldots, \mathrm{X}_{\mathrm{n}}\right\}$. Divide assessment level for different level risk factors, and the assessment level set $\mathrm{Y}=\left\{\mathrm{y}_{1}, \mathrm{y}_{2}, . ., \mathrm{y}_{\mathrm{i}}\right\}$. Then calculate the fuzzy matrix $U$, as shown in Formula (1):

$$
U=\left[\begin{array}{cccc}
u_{1}\left(y_{1}\right) & u_{1}\left(y_{2}\right) & \cdots & u_{1}\left(y_{i}\right) \\
u_{2}\left(y_{1}\right) & u_{2}\left(y_{2}\right) & \cdots & u_{2}\left(y_{i}\right) \\
\cdots & \cdots & \cdots & \cdots \\
u_{i}\left(y_{1}\right) & u_{i}\left(y_{2}\right) & \cdots & u_{i}\left(y_{i}\right)
\end{array}\right]
$$

c) Determine weight vector. After establishing multiple index system, then we need to determine the weight of each index and risk factors importance coefficient. Weight set is $A=\left\{a_{1}, a_{2}, . ., a_{n}\right\}$. Weight determination methods include Delphi, expert investigation and AHP, etc.

d) Establish membership degree. In fuzzy set theory, due to the existence of ambiguity, the relation of elements in the domain to a fuzzy subset is more than "belong" and "not belong". The membership degree of the fuzzy subset is defined as membership degree, which is between 0 and 1 .

e) Establish fuzzy evaluation matrix. First, carry out lowest level fuzzy comprehensive evaluation, then derivate the higher level fuzzy comprehensive evaluation by the evaluation results of the lowest level.

f) Obtain the final risk assessment results, according to fuzzy mathematics method as follow:

$$
B=A \cdot R
$$

g) With the evaluation index system and the membership functions and weights of each index, determine the operator of the fuzzy judgment. Then composite upper index by lower level index, and come to the conclusion of the assessment.

\section{Construction Risk Prevention Measures}

Strengthen the overall risk awareness. Objectively speaking, with the increasing competition in the construction market, architectural project without any risks does not exist, so strengthening overall risk awareness and cultivating risk culture has become an urgent current task for construction enterprises. On the one hand, should adopt various forms of the situation and tasks of education, to enhance risk awareness of employees; on the other hand, should vigorously strengthen education on the laws and regulations, which is an important prerequisite for a good job risk prevention and control.

Improve and innovate rules and regulations. To improve the risk prevention ability, we must pay great attention to the perfection and innovation of the internal regulations. First, improve and innovate the subject of rules and regulations, that is, focus on the excitation and the mobilization of the people's own spirit, thus enhance employee and enterprise risk sharing responsibility; second, improve and innovate the implementation means of rules and regulations, that is, through the implementation of the accountability system and accountability system to promote risk prevention in place; third, improve and innovate the contents of rules and regulations.

Establish a sound risk prevention mechanism. To strengthen architectural project risk prevention, the key lies in the enhancement of the risk consciousness of leaders and managers at all levels and effective operation of various mechanisms as well. Practice has proved that, only the prevention mechanism keeping pace with the times can effectively avoid the problems caused by 
various risks. First, establish sound corporate legal counsel system and legal affairs agency, to take responsible for the risk prevention and control of the whole process; second, improve corporate seal management system; establish project engineer responsibility system, in accordance with project management department and job responsibilities, confirm the relevant construction materials management content and responsibilities, and check the all construction materials regularly, so as to find out the irregularities in the construction process in time.

\section{References}

[1] A.N. Hui, C. Zheng. Evaluation of Bidding Risks on Architectural Engineering Based on ANP-Fuzzy. Construction Economy, 2013.

[2] Shun-Guo L I, L.I. Hui, Huang Q P, et al. Research on Predicting Model of Architectural Engineering Project Bidding Risk. Journal of Wuhan University of Technology, 2008, 30(7):165-168.

[3] Ju-Hui L V. Risk Management of Modern Architectural Engineering Project. Value Engineering, 2014.

[4] S.L. Wang. On risk management of architectural construction safety. Shanxi Architecture, 2013.

[5] S. Zhang. Preliminary discussion on risk prevention of architectural construction enterprises. Shanxi Architecture, 2010.

[6] G. Zheng. On exploration for risk management in construction stage of architectural projects. Shanxi Architecture, 2010. 